\title{
Hostel Management System Based on Finger Print Authentication
}

\author{
G. RAJKUMAR ${ }^{1 *}$ and T. SIVAGAMA SUNDARI ${ }^{2}$ \\ 'Department of Computer Applications, N.M.S.S.Vellaichamy Nadar College, \\ Madurai, Tamilnadu, India. \\ ${ }^{2}$ Department of Microbiology and Biotechnology, N.M.S.S.Vellaichamy Nadar College, \\ Madurai, Tamilnadu, India.
}

\begin{abstract}
The biometric system plays the most important role in this current century. Finger print identification is one among the foremost distinguished and familiar identity verification system due to its individuality. Security within the hostel is one of the foremost repetitive issues. To keep up day by day attendance verification is sophisticated and time consuming system for the hostel management. There are number of existing attending systems are available for college students, for hostel students it must improve. Within the existing system wardens are manually maintain the attendance for hostel students. This paper deals with, avoid of an entire problem in hostel management system together with this monitoring system also proposed. The administrator of this system was college principal or warden. Biometric system is used to accommodate a large number of students within the hostel. This system makes automatically to monitor the entry and exit of students from hostel and offers alert SMS to parents for their safety.
\end{abstract}

\section{Introduction}

Fingerprint identification is one of the most well-known and common biometric authentication systems. ${ }^{6}$ The system is specially proposed for hostel management and monitoring. Security in the organization is one of the most persistent issues that organization mu+st address. Nowadays security is a prime concern in each individual's life. Currently student's attendance becomes more vital element for every organization. Entering and monitoring of hostel attendance is an area of administration that can involve essential of time and effort in a hostel atmosphere. A biometrics system basically comprises entering and scrutiny biometric characteristics. ${ }^{2}$ When a person first uses a biometrics system, his or her characteristic options are entered as a reference for future comparison.

CONTACT G. Rajkumar mdugrk@gmail.com 9 Department of Computer Applications, N.M.S.S.Vellaichamy Nadar College, Madurai, Tamilnadu. India.

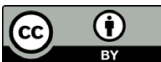

(c) 2018 The Author(s). Published by Oriental Scientific Publishing Company

This is an 2 Open Access article licensed under a Creative Commons license: Attribution 4.0 International (CC-BY).

Doi: http://dx.doi.org/10.13005/ojcst11.04.08 
Identification of the drawbacks in the present system leads to the designing of computerized system that may be compatible and user friendly.

\section{Biometric - Finger Print Recognition}

The regularly used biometric technology presently is the Fingerprint recognition, which absorbed imaging of the Fingerprint. Fingerprint recognition is widely used for certified governmental purposes whereby distinctive identification wants to be provided to every citizen, for example, ${ }^{1}$ Aadhaar ID cards provided by the 'Unique Identification Authority of India' (UIDAI). Fingerprint biometrics is favored over traditional biometric ways because during this the person to be identified is needed to be physically here at the time of identification. ${ }^{6}$

The focus is on allowing the utilization of Fingerprint biometrics technology in instructional institutions, for identification purposes. First, a Fingerprint is registered for every user. After that these image patterns are regenerate into a digital code by means of an algorithm. There are different phases in a Finger-scan authentication and identification:
Fingerprint image acquisition, image process, locating the distinctive characteristics, model creation and template matching. These stages are typically performed by a Fingerprint sensor device and attendance software package by image process techniques and image corresponding approaches.

\section{Automated Attendance System}

Attendance management is a major part of today's human resource systems. In various institutions, and academic organizations, attendance is a very essential factor which is used for different purposes. These purposes consist of record maintenance and evaluation of student's arrival. Taking of attendance is time uncontrollable and it is complicated to find out the number of students. Thus, there is a need for a system that would eliminate all of these difficulties. The Hostel management attendance system is used to verify the student's presence and for mess bill preparation.

A fingerprint sensor is electronic equipment that confines a digital image of the fingerprint pattern, by some one of the fingerprint capturing technologies

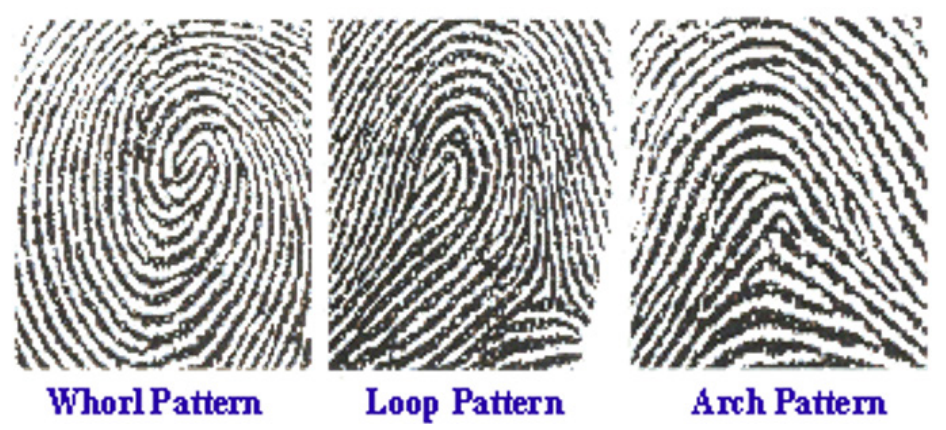

Fig.1: Finger print patterns

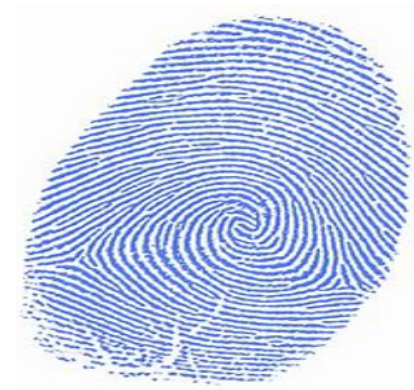

Fig. 2: Finger print

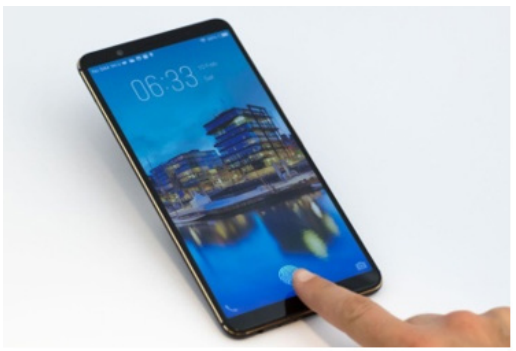

Fig. 3: Finger print technology 
that might be optical, radio frequency (RF) based. ${ }^{3}$ The confine image is acknowledged as live scan. This live scan is then digitally method by extracting choice from the fingerprint. It is then efficiently extend into a digital uniqueness of the concerned one. It is gathered in a database, for assessment desired for authentication and access power.

The attendance management system database consists of tables that accumulate records about the student's details that must correspond by an authorized person and has access to the system. Every record may contain the detail templates of the person's fingerprint and user name of the person. The database design system implements relational data model. That is a collection of tables in which data stored. This system having student's Name, ID Number, Register number, Course, Year, Room No, Photo, Fingerprint and parents mobile number that is stored in database.

\section{Proposed Model}

Hostel Management System enhances security of the hostel students. Student's daily attendance is maintained by biometric system. Student's attendance status alerts can be sent through SMS to the parents. The absentees report was very useful for the pre calculation of food preparation. This system provides an easy process for monitoring hostel student's activities by the warden. In the proposed model we can use two biometric devices; it is placed in the warden room and watchman room in main gate. The students must place their fingerprint in both of these devices. This technique increases the protection of the outlet students and used to collects the exit time and date of the students.

Along with the students attendance system their leave module and mess management also designed by this system. In mess management module we can generate mess bill preparation, mess bill collection, food preparation, stock maintenance and purchase details etc.,

The total number of exit students report was automatically sent to the PC located in the warden room. The module for student leave, permission and outing also designed with this system. After getting the initial level permission from the college, the second level parent approval also processed through SMS. Parents should provide a confirmation for their wards. After that, the gate pass was provided to the

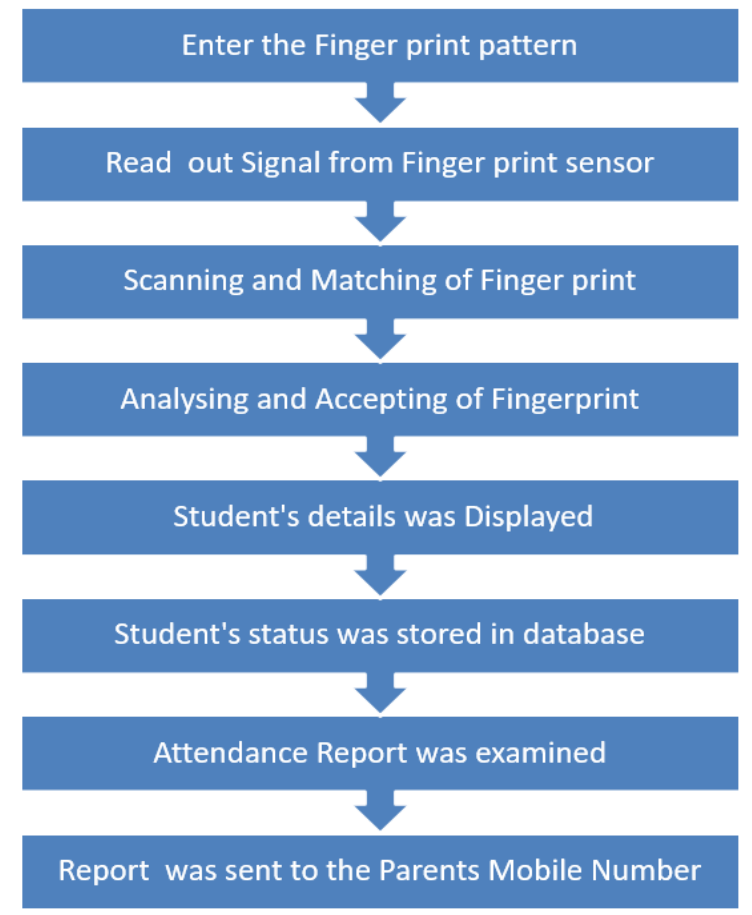

Fig. 4: Proposed Model for Hostel Management System 
students. The gate pass will be handed over to the security within the gate by the student. After inserting a thumb in the biometric sensors, the message was sent to the parents through their registered mobile number in native language. Arrival of the student to the hostel also intimated to the parents by this same method.

\section{Algorithm}

The following algorithms are more important in the hostel management system.

\section{Algorithm for Student Registration \\ Step 1}

Connect the finger print scanner and get sensor information

\section{Step 2}

Read data (Finger)

Step 3

Check - Not registered go to 5

Step 4

Print "Already exist"

Step 5

Print and stored with ID

\section{Algorithm for Attendance verification \\ Step 1}

Read the data (Finger print sensor)

\section{Step 2}

Search the data in database

Step 3

If finger not match go to Step 6

\section{Step 4}

Get the student ID and mark Present

Step 5

go to Step 1

Step 6

Print "Student name not found in the database"

Step 7

go to Step 1

Step 8

Print the Report (number of students present and absent)

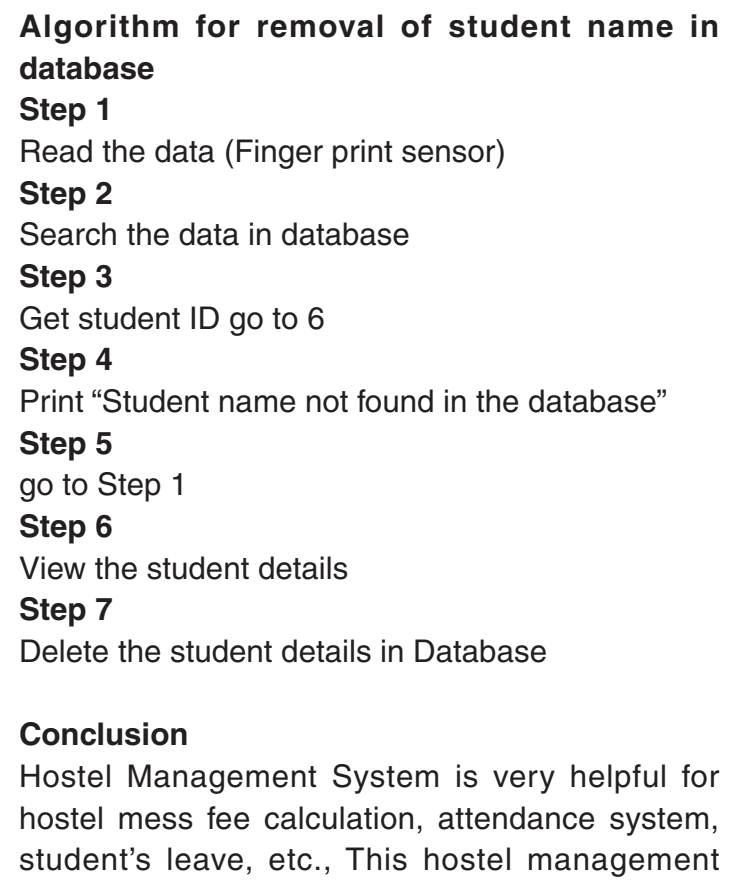
database

Step 1

Read the data (Finger print sensor)

Step 2

Search the data in database

Step 3

Get student ID go to 6

Step 4

Print "Student name not found in the database"

Step 5

go to Step 1

Step 6

View the student details

Step 7

Delete the student details in Database

\section{Conclusion}

Hostel Management System is very helpful for hostel mess fee calculation, attendance system, student's leave, etc., This hostel management

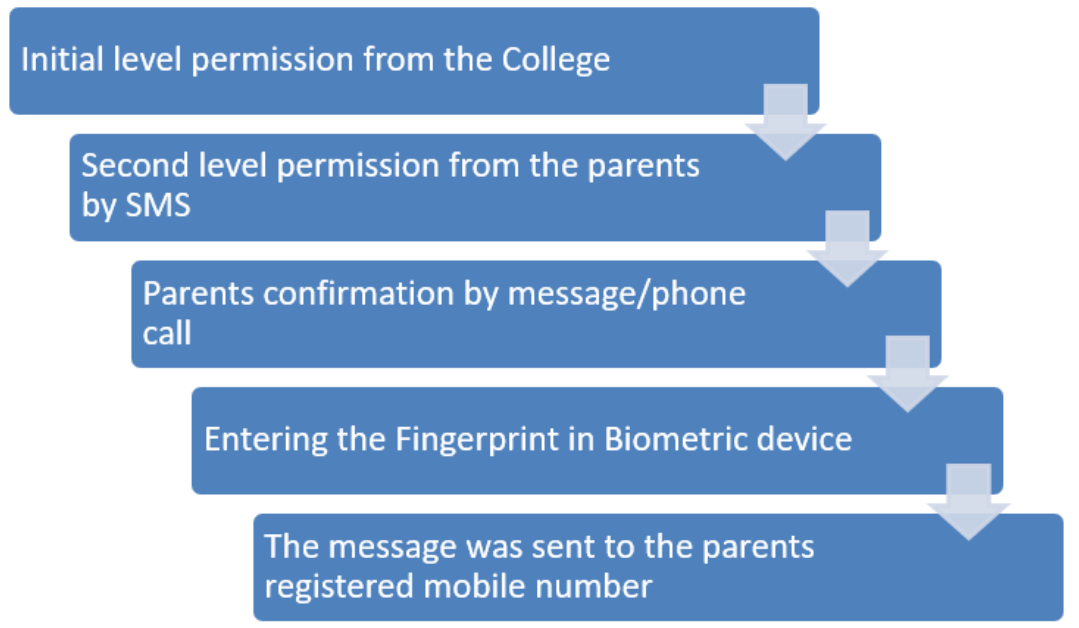

Fig. 5: Students Leave module for Hostel Management System 
software package is designed for people who wish to manage numerous activities within the hostel. This proposal will reduce manpower, and investment of the management. By this system we can easily approach and pass the information to the parents.
Biometric technology may be a reliable tool for authentication. The existing systems can further be improved or combined which helps in making the system more users friendly.

\section{References}

1. Barbadekar Ashwini, "Performance Analysis of Fingerprint Sensors", Vishwakarma Institute of Technology, Pune, 2010.

2. Mohamed Basheer KP, Raghu CV, "Fingerprint Attendance System for classroom needs", NIT Calicut, Kerala, 2012.

3. Murizah Kassim, Hasbullah Mazlan, Norliza Zaini, Muhammad Khidhir Salleh "Web-based Student Attendance System using RFID Technology" 2012 IEEE.

4. Patrick S.P.Wang and Svetlana N. Yanushkevich, Biomtric technologies and applications, AIAP '07, 25 $5^{\text {th }}$ conference on Proceedings of the IASTED, Intenational Multi conference: Artificial intelligence and applications, 2007:226 - 231.

5. Pratima Patil, Ajit Khachane and Vijay Purohit, "A Wireless Fingerprint attendance system", International Journal of Security, Privacy and Trust Management (IJSPTM), 2016, Vol. 5, No.4, November.

6. Rajan datt, Utsav Shah and Dharmin Shah, "Student Attendance Management System using Fingerprint Scanner", International
Journal of Pure and Applied Mathematics, 2018, Vol. 119, No. 16, pp. 2273 - 2278, .

7. Ruba, Rajkumar and Parimala, "Biometrics based cryptographic key generation using finger print", International Journal of Computer Engineering in Research Trends (IJCERT), June, 2017, Vol. 4, Issue 6, pp. 259 - 262.

8. Shahzad Memon, Mojtaba Sepasian, Wamadeva Balachandran, "Review of Fingerprint Sensing Technologies", Brunel University, West London, United Kingdom, 2008.

9. Sifatnur Rahman, Mahabur Rahman, Md Mijanur Rahman, "Automated Student Attendance system using fingerprint recognition", Edelweiss applied science and technology, Vol.2, Issue 1, 2018.

10. Tsai-Cheng Li1, Huan-Wen Wu, "Study of Biometrics Technology Applied in Attendance Management System", Taiwan, 2012. 11. Wayman.J, A. Jain, D. Maltoni, and D. Maio, Eds. Biometric Systems Technology, Design and Performance Evaluation, Spinger, 2005. 